\title{
Applying Communication Technology: Introducing Email and Instant Messaging in the Hospitality Curriculum
}

\author{
Amy Newman and Judi Brownell \\ Cornell University \\ Forthcoming in: \\ Journal of Hospitality, Leisure, Sport and Tourism Education
}

Amy Newman(an97@ cornell.edu) School of Hotel Administration, Cornell University, Ithaca, NY 14850. Newman is lecturer in management communication at Cornell University, School of Hotel Administration. She teaches courses in business writing, oral presentation, and corporate communication. Newman's research focuses on communication technologies. Prior to joining Cornell, she spent most of her career in corporate and external consulting roles.

Judi Brownell j1b18@cornell.edu) School of Hotel Administration, Cornell University, Ithaca, NY 14850. Brownell is professor and dean of students at Cornell University, School of Hotel Administration. She teaches courses in organizational behavior and management communication. Brownell's current research focuses on listening as it relates to communicating and maintaining service quality standards in the international cruise industry. Brownell has authored several textbooks, published over 80 articles and serves on several editorial boards. 


\begin{abstract}
Research has documented the importance and multiple uses of email and instant messaging (IM) in today's organizations. Although companies grapple with issues related to these technologies, researchers estimate that hospitality organizations are increasingly dependent on electronic communication for internal and external communication. The authors recommend a way for hospitality educators to prepare students for their future responsibilities. The knowledge and skills required to address individual and corporate-level challenges are presented in the form of a portable course unit that can be integrated into hospitality classes in a variety of disciplines.
\end{abstract}

Keywords: Hospitality; Education; Technology; Teaching methods; Email; Instant messaging 


\section{Applying Communication Technology: Introducing Email and Instant Messaging in the Hospitality Curriculum}

\section{Introduction}

Research (American Management Association [AMA], 2005; Logan et al., 2005;

Osterman Research, 2007) has documented the importance and multiple uses of email and instant messaging (IM) in today's fast-paced workplace. Given the increasing use and misuse of electronic communication, the authors propose that a portable unit be introduced into the hospitality curriculum to prepare future hospitality managers for the challenges ahead.

This paper first establishes the prevalence of email and IM and issues surrounding use of these new technologies in the workplace are reviewed. Then, to help students maximize the advantages and minimize the risks of email and IM use, the authors provide learning objectives and potential course content and activities which hospitality educators can implement in a variety of disciplines.

\section{Email and IM today}

Email is commonly used in homes and organizations. Of the 72 per cent of American adults who are online, 91 per cent use email (Fox \& Madden, 2005). At work, according to a 2004 AMA survey, 10 per cent of respondents spend more than four hours a day on email. Recent interviews with hospitality industry professionals revealed that email has become the most prevalent means of communication, with the number of daily messages received generally 
ranging from 20 for a club food and beverage director to over 100 for an e-commerce vice president (personal communication with J.K. and M.D., 21 March 2006).

In hospitality companies, email is increasingly used to communicate with external audiences. With 63 per cent of American adults using the internet to make travel reservations (Fox \& Madden, 2005), hospitality companies are reaching large audiences through email marketing and enjoying generous returns. For example, a recent email from a luxury hotel group offering room discounts generated $\$ 600,000$ in revenue (personal communication with M.D., 21 March 2006). Email is also serving as an effective feedback mechanism. This same hotel group receives a 35 per cent response rate to survey emails automatically generated when a guest checks out of a hotel (personal communication with M.D., 21 March 2006).

Unlike email, IM is akin to real-time chat and the technology of choice for young people. As students enter the workforce and as more companies become multi-national, IM is expected to increase substantially for both internal and external communication (Blackwell, 2006; Strom, 2006). According to Osterman Research (2007, Executive Summary: 1), "The demand for realtime, data sharing tools will grow ... with IM being the most popular technology (excluding Voice over Internet Protocol [VoIP]), reaching 30\% of email users today and 41\% in 2008". With presence-awareness technology, IM programs indicate when someone is online, which increases the likelihood over email of getting an immediate response. Online collaboration is easier through IM because the interaction takes place in one window. A sample IM from a global consulting firm follows:

Employee 1: do you know how to undo split screens? 
Employee 1: on excel?

Employee 2: yup

Employee 1: how?

Employee 2: go into ... one sec

Employee 2: ok highlight the column or row where the split is

Employee 2: go into Window

Employee 2: click freeze panes

Employee 2: that should do it

Employee 1: thanks!

Employee 2: no prob

According to Ritter and Rechtsteiner (2005), the average IM lasts 20 seconds, making this communication technology an efficient way to get quick answers to quick questions. A study at a Korean manufacturing company suggests improved working relationships as a result of IM use (Cho, Trier, \& Kim, 2005). Compared with a phone call, IM is generally less expensive, perceived as less intrusive, and can be retained (Bronstein \& Newman, 2006). A hotel design and construction director indicates that approximately 10 per cent of her communication is through IM (60 per cent by email). She IMs internal and supplier peers she calls 'friends', and also finds IM useful "when you know the person is at their [sic] desk" and you need a fast response (personal communication with T.K., 24 March 2006).

Given these characteristics, it is not surprising that IM is becoming more prevalent in the workplace; joining email as among the most frequently used business communication channels. 


\section{Addressing challenges of email and IM in the hospitality workplace}

With the inevitable movement towards the fast and the immediate, it becomes the responsibility of hospitality educators to ensure that students are well prepared for the communication technology challenges - and responsibilities - of tomorrow's hospitality workplace. The next section reviews issues that emerge as our students enter the workforce and use the technology available to them. Our interviews with hospitality professionals, combined with an extensive literature review, suggest that among the most troublesome issues are poor judgments regarding audience and tone, the unprofessional use of IM and email, and legal and security concerns. These emerging issues are of consequence to both the individual employee and the hospitality organization, and the classroom is the best place to prepare students to navigate the new technological landscape.

\section{Issues related to the individual}

Educators can help hospitality students understand how their use of electronic communication reflects on their individual performance and professional image. Hospitality managers, in particular, establish standards of excellence and serve as role models for communication best practices. However, IM and email, particularly over BlackBerries, are often characterized by poor grammar, incorrect punctuation, and shortened or abbreviated words. Although inaccuracy may be acceptable within limited circles of friends, young people moving into positions of responsibility must recognize the difference between casual chats and professional communications. 
As O'Connor (2005) points out, young people are now writing more, translating every thought and feeling - whatever comes into their minds - into words. This may not always be appropriate. Emotional control has also always been a hallmark of effective management practice. The temptation to respond quickly and without reflection is likely to result in a rude or angry email, which researchers have called flaming (Mills, Clay, \& Mortensen, 2000).

Further, although IM may be emerging as the channel of choice among young professionals, it is not always the most effective means for accomplishing workplace goals. A hospitality employee accustomed to contacting friends and family online may find it difficult to determine when a telephone call or a face-to-face meeting may be the best choice. In some cases, using "hybrid strategies", or multiple forms of communication, may be most appropriate (Shipley \& Schwalbe, 2007, p. 46). With increasing options regarding the communication channels available to them, employees' decisions become more and more complex.

\section{Issues related to the corporation}

An individual's professional image affects the organization as a whole. The misuse of electronic communication, however, also can have broader and more tangible consequences. A 2005 AMA study revealed that 24 per cent of companies have had employee email subpoenaed, and 13 per cent have 'battled lawsuits triggered by employee email'. IM can be damaging as well: 24 per cent of employees admit to sending jokes, gossip and disparaging remarks through IM (AMA, 2005). Such messages can be saved indefinitely by a large number of intended - or unintended - recipients. 
Failure to implement policies on the proper use of electronic communication leaves hospitality organizations vulnerable to legal and security issues (Flynn, 2004). IM brings threats of worms, Trojan horses, data theft and impersonation; however, only 42 per cent of organizations have IM policies in place (AMA, 2005). Policies regarding personal email use are more common, at 84 per cent, and 55 per cent of employers retain and review workers' emails (AMA, 2005). Still, hospitality companies can do a better job of protecting themselves by educating employees - as faculty are educating students - on the risks involved and how to defend against them.

\section{A portable unit on email and IM}

Hospitality educators play an important role in preparing students for new workplace challenges. A success factor for hospitality managers will be how effectively they communicate in an increasingly electronic business environment. Sample material for a portable unit on email and IM in the hospitality workplace is provided in the Appendix and, after the unit rationale, learning objectives and content and activities are presented to illustrate how some of the objectives might be approached in the classroom. As an essential component of students' professional preparation, an entire unit, or portions of it, may be integrated into courses in such disciplines as organizational behavior, information systems, human resources, hospitality law, marketing, and management communication.

\section{Conclusion}

By recognizing and addressing the challenges of electronic communication, educators can support hospitality students as they move into positions of responsibility. A more 
knowledgeable workforce with an improved understanding of communication technologies will also ensure that email and IM have a positive impact at the organizational level, enhancing corporate image and avoiding legal and security issues. Technology will continue to have a profound impact on hospitality organizations and their employees. Those who are well prepared to meet the challenges ahead will have a competitive advantage that can only increase as new technologies are continually introduced into the workplace. 


\section{References}

American Management Association Research (2005). 2005 Electronic monitoring and surveillance survey. Retrieved on January 18, 2008 from http://www.amanet.org/research/pdfs/EMS_summary05.pdf

American Management Association Research (2004). 2004 Workplace e-mail and instant messaging survey summary. Retrieved January 16, 2006 from http://www.amanet.org/research/pdfs/IM_2004_Summary.pdf

Blackwell, L. (2006). Instant messengers grow up and go to work. PC World, 24(2), 66.

Bronstein, J. \& Newman, A. (2006). IM 4 learning. T+D Magazine, 60(2), 47-51.

Cavanagh, C. (2003). Managing your e-mail: Thinking outside the inbox. Hoboken, NJ: John Wiley \& Sons, Inc.

Cho, H. K., Trier, M., \& Kim, E. (2005). The use of instant messaging in working relationship development: A case study. Journal of Computer-Mediated Communication, 10(4), article 17. Retrieved on January 6, 2008 from http://jcmc.indiana.edu/vol10/issue4/cho.html

Flynn, N. (2004). Instant messaging rules: A business guide to managing policies, security, and legal issues for safe IM communication. New York, NY: AMACOM.

Fox, S., \& Madden, M. (2005, December). Generations online. Pew Internet and American Life Project. Retrieved on March 26, 2006 from http://www.pewinternet.org/pdfs/PIP_Generations_Memo.pdf

Logan D. , Knox, R. E., Andrews, W., Caldwell, F., Lundy, J., \& Shegda, K. M. (2005, July 25). Hype cycle for the high-performance workplace, 2005. Retrieved on January 16, 2006 from http://gartnerweb.cit.cornell.edu/intraweb/research/127600/127668/127668.html 
Mills, J. E., Clay, J., \& Mortensen, M. (2000). You've got trouble! Managing e-mail liability. Cornell Hotel and Restaurant Administration Quarterly, 41(5), 64-71.

Munter, M. (2006). Guide to Managerial Communication. Upper Saddle River, NJ: Pearson Education, Inc.

O’Connor, A. (2005). Instant messaging: Friend or foe of student writing? New Horizons. Retrieved on July 27, 2005 from http://www.newhorizons.org/strategies/literacy/oconnor.htm

Osterman Research (2007, August). Presence, IM and Real-Time Communication Trends, 20072010.

Osterman Research Executive Summary. Retrieved on January 12, 2008 from http://www.theinfoshop.com/study/or49530-im-communi.html

Ritter, P., \& Rechtsteiner, C. (2005). The business case for enterprise instant messaging. Wainhouse Research. Retrieved on July 1, 2005 from http://www.parlano.com

Shipley, D., \& Schwalbe, W. (2007). Send: The essential guide to email for office and home. New York, NY: Knopf.

Strom D. (2006, April 5). I.M. generation is changing the way business talks. The New York Times, G.4.

Tapper, J. (2006, February 18). The e-mail spat that landed in cyberspace. ABCNews.com. Retrieved on January 6, 2008 from http://abcnews.go.com/Nightline/story?id=1635684

Tiliacos, J. (2006, March 30). American Airlines: To all flight attendants. Retrieved on January 6, 2008 from http://www.westga.edu/ bquest/2005/memos.pdf 


\section{Appendix}

\section{Effective use of email and IM in the hospitality workplace: a portable instructional unit}

\section{Unit rationale}

- Young people use electronic communication extensively in their personal lives.

- We cannot ignore the potential impact of email and IM in the hospitality workplace, particularly given the prevalence and increasing importance of technology to the industry.

- Students will face challenges in making the transition to using these technologies appropriately and effectively at work.

- Consequences of misusing the technology are serious for the individual and the organization.

\section{Learning objectives}

After completing this unit, students will:

Issues related to the individual

- Understand that communication through email and IM is an important component of an organization's service orientation

- Choose appropriate mediums to reach communication objectives as effectively and efficiently as possible

- Apply a sound decision-making process to all written communication to ensure that email and IMs enhance and do not damage relationships

- Distinguish between formal and informal communication and appropriately apply principles of style and tone 
Issues related to the corporation

- Become aware of how individual communications affect constituencies' perceptions of the entire organization

- Understand how features of electronic communication increase the risks of litigation and security violations

- Develop an email and IM policy for a hospitality organization

\section{Sample content and activities}

Issues related to the individual

Objective: Understand that communication through email and IM is an important component of an organization's service orientation

Content: Email and IM in hospitality companies (lecture and discussion: 30 minutes)

- Introduce this section by providing data to show the prevalence of email and IM in business. Provide examples of how companies use email and IM internally and externally in hospitality companies.

- Facilitate a discussion to demonstrate that email and IM communication is a reflection of a company's service orientation. Discuss a manager's role in modeling effective communication through email and IM.

- Review examples of emails and IMs and solicit student reactions. Consider showing current, published email exchanges (for example, Tapper, 2006).

Objective: Apply a sound decision-making process to all written communication to ensure that email and IM enhance and do not damage relationships 
Content: Writing emails and IMs to maintain and build relationships (lecture, discussion and activity: 30 minutes)

- Review a recommended writing process (for example, Munter, 2006) and discuss adaptations for email and IM communication. Emphasize the importance of applying good writing principles (for example, organization, conciseness) to short, electronic communications.

- Facilitate a discussion on balancing writing effective messages and speed. Discuss examples from the instructor's and students' experience of messages that were sent hastily and describe the negative impact on relationships.

- Provide hospitality examples of emails relevant to the course discipline that demonstrate appropriate and inappropriate decision-making (for example, Tiliacos, 2006). Assign samples for students to analyze in teams.

Objective: Distinguish between formal and informal communication and appropriately apply principles of style and tone

Content: Tone and formality in email and IM (lecture, discussion and activities: 40 minutes)

- Assign as homework: Students write an email and post it to Blackboard or WebCT (for example, requesting a deadline extension from their manager or responding to a guest complaint).

- Introduce concepts of style and tone. Draw a 'formality continuum' (a long line with arrows on the ends) on a white board. Ask students where they would place communications such as IMs, emails, proposals, resumes, etc. Explain that IMs typically are at the 'informal' end, while email messages extend across the continuum, depending 
on the message (for example, short emails to schedule meetings may be informal, while longer emails with contracts or resumes attached are typically more formal). Explain that formality of communications also depends on the organizational culture; provide examples of hospitality companies.

- Facilitate a discussion on grammar, capitalization and punctuation in emails and IMs. Encourage students to consider factors about the organizational culture and their audience (for example, level, internal vs. external, how well they know the person, if they have sent IMs to this person before, etc.) before deciding whether to dispense with proper grammar, capitalization and punctuation. Encourage students to err on the side of too much formality.

- Compare student Blackboard or WebCT posts in class, with a focus on tone and which emails are most likely to achieve the objective.

- Assign as homework: Students initiate an IM to the instructor, asking a question about course content or an upcoming assignment. Evaluate IMs in class.

- Encourage students to IM with the instructor outside class.

\section{Issues related to the corporation}

Objective: Understand how features of electronic communication increase the risks of litigation and security violations

Content: Legal and security issues (activity, lecture and discussion: 20 minutes)

- Begin the section with a quiz to explain the legal and security issues of email and IM.

- Discuss examples of recent cases involving email and IM (for example, harassment, defamation, political). 
- Facilitate a discussion on ways individuals and companies can protect themselves (see Cavanagh, 2003). 